\title{
PARÂMETROS INDICATIVOS DO PROCESSO DE SALINIZAÇÃO EM RIOS URBANOS DO SEMI-ÁRIDO BRASILEIRO
}

\author{
José Soares dos Santos*, Marcio José Silva dos Santos e Maria Lúcia Pires dos Santos \\ Departamento de Ciências Naturais, Universidade Estadual do Sudoeste da Bahia, Estrada do Bem Querer, km 4, \\ CP 95, 45083-900 Vitória da Conquista - BA, Brasil
}

Recebido em 13/8/08; aceito em 28/1/09; publicado na web em 23/7/09

\begin{abstract}
INDICATIVE PARAMETERS OF THE SALT ACCUMULATION URBAN RIVERS IN THE BRAZILIAN SEMI-ARID AREA. This study examined the spatial and temporal variations of six important parameters of the salt accumulation process in water samples collected along section urban of Contas River. The $\mathrm{Na}^{+}, \mathrm{K}^{+}, \mathrm{Ca}^{2+}$ and $\mathrm{Mg}^{2+}$ concentrations were determined by FAAS. The conductivity, total dissolved solids, $\mathrm{Na}^{+}$and $\mathrm{Ca}^{2+}$ presented the largest seasonal and spatial variations in the urban area demonstrated that are appropriate indicators of urban contamination. The readily soluble salts in drainage urban, contribute for the degradation of the water of rivers located in semi-arid zones.
\end{abstract}

Keywords: salt accumulation; Contas River; semi-arid zones.

\section{INTRODUÇÃO}

A circulação e distribuição das espécies químicas nos sistemas aquáticos são relativamente bem definidas, entretanto, sua dinâmica é influenciada pelas variações climáticas. As sucessões de estações chuvosas e secas correspondem, para as águas dos rios, à alternância de diluição e concentração das espécies químicas. ${ }^{1-11}$

As recentes mudanças climáticas estão provocando alterações nos padrões hidrológicos dos sistemas aquáticos, especialmente nos rios brasileiros localizados nas zonas semi-áridas. ${ }^{1,2}$ Tal fato é observado, devido à intensificação da irregularidade dos regimes de chuva, que estão provocando secas mais frequentes.

A Bacia do Rio de Contas, com área de $55.335 \mathrm{~km}^{2}$, a mais importante do Sudoeste da Bahia, é quase toda formada por terrenos cristalinos, nos quais os recursos subterrâneos de água são escassos. O aumento da disponibilidade hídrica tem sido efetivado pela ativação dos recursos de superfície, sendo que atualmente existem mais de duas dezenas de açudes de grande e médio porte, com uma capacidade disponível total de armazenamento de mais de 2 bilhões de $\mathrm{m}^{3}$ de água, da qual um volume significativo se encontra com a qualidade deteriorada devido ao processo de salinização. ${ }^{1,3}$

Para identificar a tendência da salinização, Santos et al. ${ }^{1}$ determinaram sódio, potássio, cálcio e magnésio em amostras de água coletada em reservatórios e seus afluentes localizados na Bacia do Rio de Contas. Observaram que nas represas construídas sem planejamento adequado (demanda irregular) estão ocorrendo degradações dos recursos hídricos, devido à concentração por evaporação dos elementos presentes em solução, que crescem com a idade dos reservatórios. Constataram que, em represas de demanda regular, o parâmetro que governa a variação da concentração das espécies químicas dissolvidas é o tempo de retenção hidráulica. As relações entre sazonalidade, $\mathrm{pH}$ e concentração dos elementos demonstram a influência do valor do pH, nas concentrações de cálcio e magnésio, principalmente quando as concentrações estiveram próximas dos limites de saturação. ${ }^{1}$

O rio de Contas, no seu curso médio, corta o município de Jequié de oeste para leste, sendo que o perímetro urbano se localiza às suas margens. Trata-se de uma drenagem perene com grande

*e-mail: zesoares@uesb.br importância regional. Esse percurso encontra-se em processo de degradação intensa e permanente. Tal processo vem se intensificando a partir do final da década de 80 com o crescimento desordenado da cidade de Jequié.

A proposta deste trabalho surgiu pela preocupação em se avaliar a influência dos escoamentos urbanos na salinização de rios localizados no semi-árido brasileiro. Para avaliar a dinâmica desse processo, foi escolhida uma faixa do Rio de Contas que compreende a Represa Pedras e o perímetro urbano da cidade de Jequié no sudoeste do estado da Bahia. Para isso, em amostras de água coletadas em pontos distribuídos no percurso em estudo, foram realizadas medidas de condutividade elétrica, sólidos totais dissolvidos e pH e determinações das concentrações de algumas das principais espécies químicas dissolvidas em águas superficiais urbanas $\left(\mathrm{Ca}^{2+}, \mathrm{Mg}^{2+}, \mathrm{Na}^{+}\right.$e $\left.\left.\mathrm{K}^{+}\right)\right)^{1-4}$

O Rio de Contas apresenta um fluxo de água muito variável conforme a estação do ano. A Represa Pedras foi construída há aproximadamente 30 anos sobre o curso do Rio de Contas, visando armazenar água no período chuvoso para disponibilizar no período seco. Os impactos mais relevantes associados às águas do Rio de Contas no local em estudo referem-se ao lançamento de efluentes líquidos, disposição de resíduos sólidos e drenagem dos escoamentos urbanos nos seus principais tributários.

\section{PARTE EXPERIMENTAL}

\section{Descrição da área em estudo}

O estudo foi realizado no curso médio do Rio de Contas, em uma área que engloba o perímetro urbano e parte da zona rural do município de Jequié, localizado no sudoeste do estado da Bahia (latitude $13^{\circ} 51^{\prime} 51^{\prime}$ 'Sul, longitude $40^{\circ} 04^{\prime}$ 54" Oeste e altitude de $188 \mathrm{~m}$ ). O clima é típico das zonas semi-áridas, apresentando chuvas médias anuais abaixo de $700 \mathrm{~mm}$, que ocorrem quase que exclusivamente durante os meses de verão. Com isso, a maioria dos tributários do Rio de Contas neste percurso é intermitente ou efêmero.

Geologicamente, a região é representada, predominantemente, por rochas cristalinas do complexo Jequié e, em menor proporção do complexo Ibicuí-Ipiaú, cortados por corpos máficos e granitos. ${ }^{12}$ 


\section{Procedimento de coleta}

Inicialmente, realizou-se um estudo amplo no Rio de Contas, no percurso que compreende o Reservatório Pedras até o sítio urbano da cidade de Jequié. A represa foi construída na década de 1970, sobre o curso do Rio de Contas com a finalidade de gerar energia elétrica. Em seguida, foi estabelecido um calendário de coleta de água e sedimento em pontos distribuídos no corpo Reservatório Pedras e no curso do rio.

Os pontos de coleta, mostrados na Figura 1S (Material Suplementar), foram distribuídos visando uma melhor estratégia para o estudo da dinâmica do processo de salinização, tendo como base os aspectos geomorfológicos dos corpos de água. Os pontos $\mathrm{P} 1 \mathrm{e}$ P2 localizam-se, respectivamente, no corpo principal e na comporta do Reservatório Pedras. Os pontos P3, P4 e P5, no Rio de Contas, foram escolhidos com objetivo de se avaliar a influência do deflúvio urbano na concentração das espécies químicas dissolvidas ao longo do rio. O ponto P6 localiza-se a aproximadamente $6 \mathrm{~km}$ a jusante do perímetro urbano de Jequié. Cada uma das estações de coleta foram georreferenciadas com base no sistema de posicionamento global GPS (global position system).

Devido à variação sazonal de importantes parâmetros reguladores da dinâmica das espécies químicas nestes corpos de água, causada pela distribuição irregular de chuvas na região, o planejamento para coleta teve como base a distribuição anual de chuvas na região, conforme mostrado na Figura 1. As campanhas para coletas foram realizadas seguindo o cronograma: início da estação chuvosa (05/12/2005), período seco (12/09/2006), estação chuvosa (26/11/2006), final da estação chuvosa (08/04/2007) e plena de seca (03/07/2007).

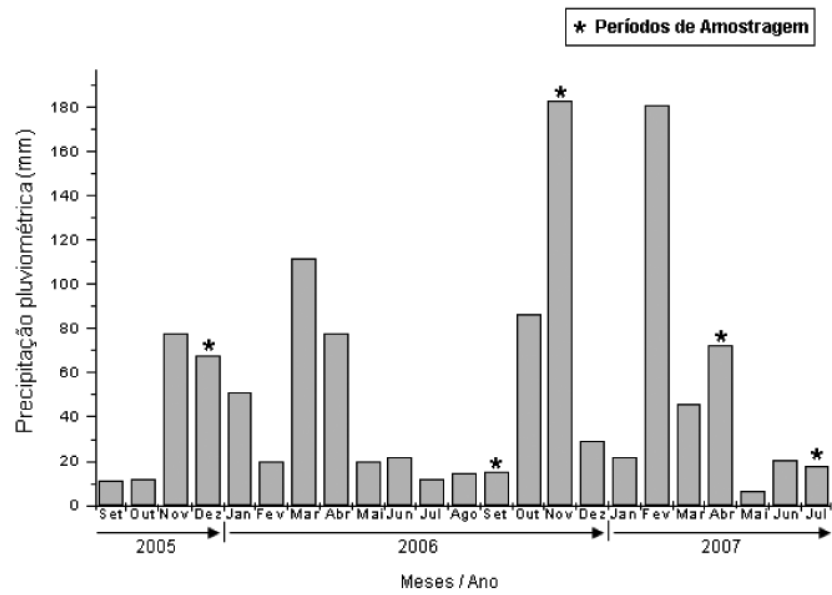

Figura 1. Gráfico demonstrando a evolução temporal das chuvas durante o período de coleta

Para se evitar a introdução de contaminantes superficiais, as amostras de água foram coletadas a uma distância de $2 \mathrm{~m}$ da margem, mergulhando frascos de polietileno até uma profundidade de $50 \mathrm{~cm}$. A seguir, o frasco foi direcionado de modo que a boca ficasse no sentido contrário à correnteza. Finalmente, inclinou-se o frasco lentamente para cima a fim de permitir a saída do ar e seu consequente enchimento com água. Após a retirada do frasco do corpo de água, desprezou-se uma pequena porção da amostra, deixando um espaço vazio suficiente que permitisse a homogeneização da amostra; a seguir, as amostras foram preservadas pela adição de ácido nítrico até $\mathrm{pH}$ 2. As amostras destinadas a medidas de $\mathrm{pH}$, condutividade elétrica (CE) e sólidos totais dissolvidos (STD) foram preservadas apenas com gelo e mantidas a aproximadamente $4{ }^{\circ} \mathrm{C}$ até a análise.

\section{Reagentes e soluções}

Para a determinação de metais, as soluções estoque foram preparadas a partir de soluções padrão (Accustandart/SpecSol) de concentração $1000 \mathrm{mg} \mathrm{mL}^{-1}$ e água deionizada purificada através do sistema Milli-Q (Millipore) até alta pureza (resistividade $18 \mathrm{M} \Omega$ $\mathrm{cm}^{-1}$ ) e acondicionadas em frascos de polietileno pré-lavados com $\mathrm{HNO}_{3} 10 \%$. As soluções de trabalho foram obtidas por diluição das soluções estoque. Um branco foi preparado com $\mathrm{HNO}_{3} 1 \%$ em água deionizada e estocado da mesma forma. Para obtenção das curvas analíticas as soluções de referência foram preparadas por diluição serial das soluções estoque $1000 \mathrm{mg} \mathrm{mL}^{-1} \mathrm{em}$ água deionizada.

\section{Procedimentos analíticos}

As determinações dos elementos $\mathrm{Na}, \mathrm{K}, \mathrm{Ca}$ e $\mathrm{Mg}$ nas amostras de água foram realizadas empregando um espectrômetro de absorção atômica por chama (FAAS), modelo AAnalyst 200 (USA) equipado com corretor de fundo de deutério. A resposta do instrumento foi conferida periodicamente com soluções padrão de concentração conhecida. O sistema de aquisição de dados foi gerenciado por microcomputador acoplado ao espectrômetro de absorção atômica e, como fontes de radiação, foram empregadas lâmpadas de cátodo oco dos respectivos elementos. Com base nas recomendações do fabricante a chama ar-acetileno foi utilizada na quantificação dos quatro elementos em estudo. Para obtenção dos sinais de absorção do $\mathrm{K}, \mathrm{Ca}$ e $\mathrm{Mg}$ foram utilizados os seguintes parâmetros: largura de fenda de $0,7 \mathrm{~nm}$ e comprimentos de onda (766, 423 e $285 \mathrm{~nm}$, respectivamente). Para o $\mathrm{Na}$ o comprimento de onda utilizado foi de $589 \mathrm{~nm}$ e abertura da fenda de $0,4 \mathrm{~nm}$. Devido à inexistência de um equipamento de fotometria de chama, as determinações de $\mathrm{Na}$ e $\mathrm{K}$ foram realizadas por FAAS, entretanto, para controlar a ionização desses elementos, adicionou-se $\mathrm{CsCl}(0,1 \%)$ nos padrões e nas amostras. Para evitar a interferência de alguns elementos existentes na matriz durante a determinação de $\mathrm{Ca}$ e $\mathrm{Mg}$, adicionou-se $\mathrm{LaCl}_{2}$ $(0,1 \%)$ nos padrões e nas amostras.

As análises físico-químicas foram realizadas utilizando-se $\mathrm{pHme-}$ tro de bancada Digimed, modelo DM 20; condutivímetro de bancada CAAL, modelo MCA-150.

\section{RESULTADOS E DISCUSSÃO}

Durante o processo de urbanização, a construção da infraestrutura - como ruas, calçadas, estruturas comerciais e residenciais - normalmente é projetada para coletar as águas das chuvas e carregá-las para fora do perímetro das cidades, através de canais superficiais existentes, como os fluxos dos rios e córregos. As águas de chuvas que fluem sobre as cidades carregam poluentes que podem deteriorar a qualidade dos recursos hídricos superficiais. Com isso, as águas das enxurradas urbanas podem provocar aumentos nos teores de sólidos totais dissolvidos (STD) e nas concentrações de sais solúveis, influenciando o valor da medida da condutividade elétrica $(\mathrm{CE})$. $^{13-17}$

Os teores de metais dissolvidos na coluna d'água tendem a variar em muitas ordens de magnitude ao longo do tempo e dos diferentes pontos de amostragem, o que se deve ao grande número de variáveis envolvidas na sua dinâmica, tais como variações diárias e sazonais no fluxo d'água, descargas locais de efluentes urbanos e industriais, variações de $\mathrm{pH}$ e condições redox, níveis de detergentes, salinidade e temperatura. Apesar dessas variações, a determinação das concentrações dos metais dissolvidos na água constitui uma ferramenta útil na avaliação do grau de contaminação de um determinado ecossistema. ${ }^{18,19}$ 
O estudo foi conduzido com base na determinação das concentrações de $\mathrm{Na}, \mathrm{K}, \mathrm{Mg}$ e Ca e medidas de pH, condutividade elétrica (CE) e sólidos totais dissolvidos (STD) em amostras de água coletadas em cada estação de amostragem. A Figura 2 mostra as variações da CE e de STD nas amostras coletadas nos períodos seco e chuvoso. As medidas da CE e STD apresentaram os maiores valores no período chuvoso, destacando-se as águas coletadas no ponto P5, local de drenagem da maior parte do escoamento urbano da cidade de Jequié.
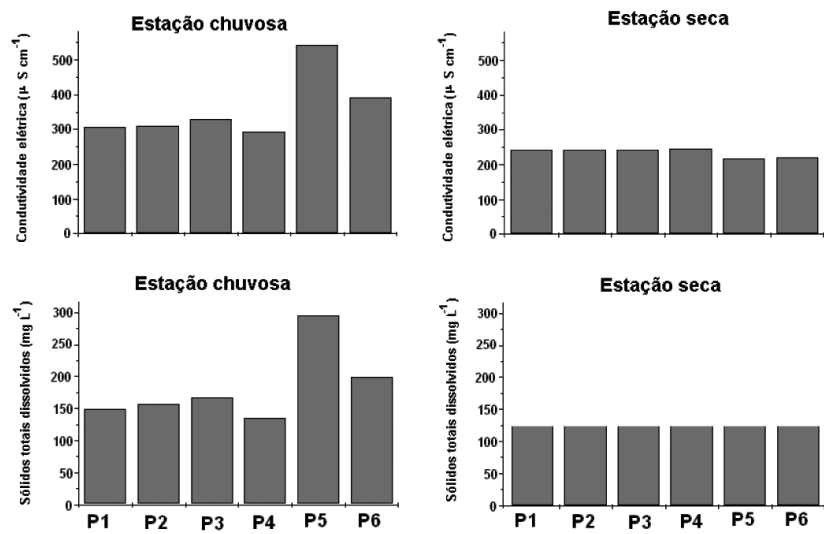

Figura 2. Variação da condutividade (CE) e sólidos totais dissolvidos (STD) nas amostras de água coletadas nos períodos seco e chuvoso

\section{Comportamento de $\mathrm{Na}, \mathrm{K}$, Ca e Mg no ambiente em estudo}

$\mathrm{Na}, \mathrm{K}, \mathrm{Ca}$ e $\mathrm{Mg}$ são os elementos de maior abundância nas águas superficiais e encontram-se associados principalmente com $\mathrm{Cl}^{-}$e $\mathrm{HCO}_{3}^{-}$e, em menor quantidade, com $\mathrm{CO}_{4}^{2-}, \mathrm{SO}_{4}{ }^{2-}$ e $\mathrm{NO}_{3}{ }_{3}^{-}$, formando sais altamente solúveis. Em consequência, os íons $\mathrm{Na}^{+}$, $\mathrm{K}^{+}, \mathrm{Ca}^{2+}$ e $\mathrm{Mg}^{2+}$ são as principais espécies químicas dissolvidas encontradas nas águas superficiais naturais. Estudos realizados por Santos et al. ${ }^{1}$, para avaliar a dinâmica do processo de salinização nos reservatórios hídricos localizados no semi-árido brasileiro, indicaram que $\mathrm{Na}, \mathrm{K}, \mathrm{Ca}$ e $\mathrm{Mg}$ constituem importantes parâmetros indicativos do processo de concentrações por evaporação (salinização) das espécies químicas dissolvidas nas águas dos reservatórios superficiais.

Com base nos resultados apresentados na Tabela 1, pode-se observar que no período seco, os teores de sódio, potássio, cálcio e magnésio, avaliados nas águas do rio de Contas em pontos distintos, apresentaram-se concordantes, embora apreciavelmente diferentes em um e outro caso. Em setembro de 2006 (primeiro período seco avaliado) as amostras de água apresentaram um aumento progressivo dos teores de sódio entre os pontos P2 e P5. O aumento da concentração de sódio observada na faixa semiurbana localiza entre os pontos $\mathrm{P} 2$ e $\mathrm{P} 3$ pode ser atribuída à existência de uma área de agricultura irrigada no local. O processo contínuo de irrigação resulta na adição de sais solúveis no solo, tais como sódio, cálcio, magnésio, potássio, sulfato e cloreto. Como resultado ocorre um aumento da salinidade das águas localizadas a jusante da área de irrigação, o que pode comprometer o uso dessas águas para determinados fins. Já na faixa que abrange os pontos P4 e P5, o aumento dos teores de sódio pode ser atribuído à influência das atividades urbanas, tendo em vista que nesse percurso o Rio de Contas começa a receber os despejos de esgoto sanitário e águas pluviais drenados por um sistema de coleta combinado através de galerias e emissários.

Em julho de 2007 (segundo período seco avaliado) as espécies dissolvidas apresentaram valores similares em todos os pontos de coleta, com exceção do cálcio que apresentou um aumento progressivo no percurso, como mostra a Figura 3.

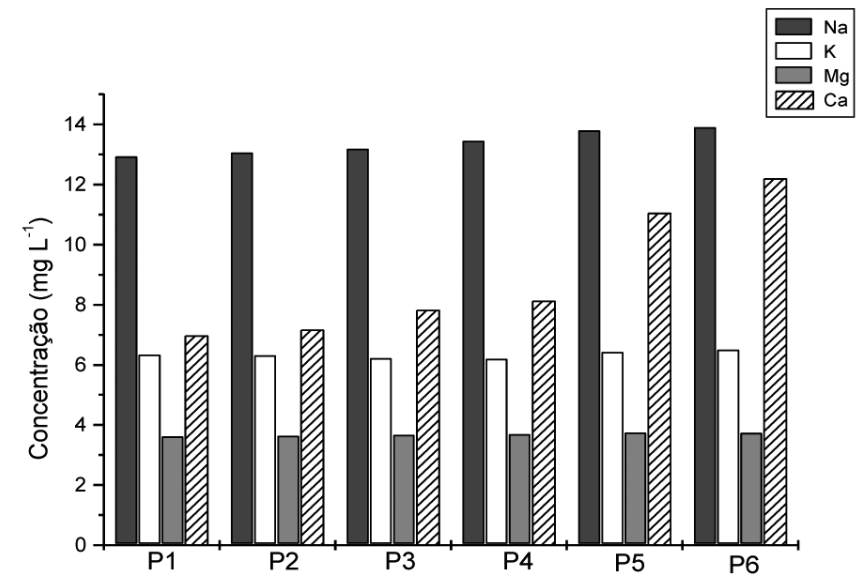

Figura 3. Gráfico das concentrações de $\mathrm{Na}, \mathrm{K}, \mathrm{Ca}$ e Mg nas amostras de água coletadas em julho de 2007

Em dezembro de 2005 (período chuvoso) os teores de sódio, cálcio e magnésio apresentaram-se muito similares na maioria dos pontos de coleta; a única exceção foi para o cálcio e o sódio nas águas coletadas no ponto $\mathrm{P} 4$. Neste período esses elementos apresentaram um enriquecimento em suas concentrações em torno de 3 vezes maiores para o Ca e 1,5 vezes maiores para o Na quando comparadas com as águas dos demais pontos. Isso pode ser atribuído à influência da localização. Este ponto está situado exatamente na zona de encontro das águas do Rio de Contas com o Rio Jequiezinho, cujo canal vem sendo utilizado para drenar boa parte do esgoto sanitário e do deflúvio urbano da cidade de Jequié.

No final da estação chuvosa (abril de 2007), pode-se observar que o sódio apresentou um aumento progressivo em sua concentração, a partir da Represa Pedras até o perímetro urbano da cidade de Jequié, ou seja, no intervalo entre o ponto P1 e o ponto P6. Esse comportamento, conforme discutido anteriormente, pode ser atribuído as descargas dos efluentes do processo de irrigação, esgotos sanitários e águas pluviais da cidade.

\section{Variações temporais e espaciais dos parâmetros em estudo}

Devido à superposição dos diferentes fatores (evapoconcentração, enchentes e poluição), que afetam a mobilidade dos metais nos recursos hídricos, foram utilizados diagramas ternários, Figuras 4 e 5 , gerados a partir da proporção relativa das concentrações dos íons majoritários $\mathrm{Na}^{+}, \mathrm{K}^{+}$e $\mathrm{Ca}^{2+}$. Estes diagramas constituem importantes ferramentas que podem ser utilizadas para caracterização das águas naturais e avaliar as variações sofridas em suas composições, quando ocorrem aportes de resíduos provocados por ações naturais ou antropogênicas.

A partir de uma análise global, fica evidente que as sucessões de estações chuvosas e secas correspondem, para as águas dos três primeiros pontos de coleta (P1, P2 e P3), à alternância de diluição e concentração de espécies $\mathrm{Na}^{+}, \mathrm{K}^{+}$e $\mathrm{Ca}^{2+}$. De acordo com a Figura 4, não ocorreram variações significativas nos padrões de distribuição dessas espécies químicas nos diagramas ternários, gerados a partir da composição das amostras de água dos três referidos pontos, coletadas nos cinco períodos. No período seco, o complexo rio/Represa apresenta pouco volume de água, ou seja, pouca diluição, enquanto no período chuvoso, apresenta seu maior volume de água provocando, assim, a diluição das espécies dissolvidas.

Para os pontos que recebem uma maior influência da atividade urbana (P4, P5 e P6), a Figura 5 mostra que os padrões de distribuição 
Tabela 1. Concentração média de $\mathrm{Na}, \mathrm{K}, \mathrm{Ca}$ e $\mathrm{Mg}$ em $\left(\mathrm{mg} \mathrm{L}^{-1}\right)$ e medidas de $\mathrm{pH}$ das amostras de água coletadas no Rio de Contas e Reservatório Pedras

\begin{tabular}{|c|c|c|c|c|c|c|c|}
\hline & & $\mathrm{P} 1$ & $\mathrm{P} 2$ & $\mathrm{P} 3$ & P4 & P5 & P6 \\
\hline \multirow[t]{5}{*}{ Dez/2005 } & $\mathrm{pH}$ & 7,16 & 7,47 & 7,91 & 7,46 & 7,50 & 7,28 \\
\hline & $\mathrm{Na}$ & $31,9 \pm 0,2$ & $32,2 \pm 0,1$ & $34,3 \pm 0,2$ & $51,9 \pm 0,2$ & $35,5 \pm 0,3$ & $36,1 \pm 0,2$ \\
\hline & $\mathrm{K}$ & $10,8 \pm 0,1$ & $11,1 \pm 0,1$ & $11,2 \pm 0,1$ & $7,20 \pm 0,21$ & $11,5 \pm 0,1$ & $11,9 \pm 0,1$ \\
\hline & $\mathrm{Ca}$ & $11,7 \pm 0,1$ & $11,7 \pm 0,2$ & $11,8 \pm 0,2$ & $38,9 \pm 0,2$ & $12,1 \pm 0,2$ & $12,1 \pm 0,2$ \\
\hline & $\mathrm{Mg}$ & $2,85 \pm 0,13$ & $2,89 \pm 0,12$ & $2,85 \pm 0,20$ & $3,16 \pm 0,11$ & $2,89 \pm 0,22$ & $2,87 \pm 0,10$ \\
\hline \multirow[t]{5}{*}{ Set/2006 } & $\mathrm{pH}$ & 7,15 & 7,08 & 8,24 & 8,23 & 8,30 & 7,29 \\
\hline & $\mathrm{Na}$ & $33,8 \pm 0,3$ & $28,3 \pm 0,3$ & $33,8 \pm 0,2$ & $36,0 \pm 0,2$ & $48,0 \pm 0,1$ & $41,5 \pm 0,1$ \\
\hline & K & $7,13 \pm 0,30$ & $5,44 \pm 0,30$ & $6,57 \pm 0,31$ & $6,57 \pm 0,21$ & $8,25 \pm 0,12$ & $7,13 \pm 0,24$ \\
\hline & $\mathrm{Ca}$ & $8,49 \pm 0,42$ & $8,55 \pm 0,33$ & $9,61 \pm 0,20$ & $9,39 \pm 0,21$ & $9,63 \pm 0,20$ & $9,46 \pm 0,20$ \\
\hline & $\mathrm{Mg}$ & $8,86 \pm 0,22$ & $10,3 \pm 0,2$ & $9,16 \pm 0,13$ & $9,44 \pm 0,12$ & $10,1 \pm 0,1$ & $9,66 \pm 0,20$ \\
\hline \multirow[t]{5}{*}{ Nov/2006 } & $\mathrm{pH}$ & 7,25 & 7,11 & 6,90 & 7,20 & 7,06 & 6,85 \\
\hline & $\mathrm{Na}$ & $26,9 \pm 0,2$ & $31,9 \pm 0,2$ & $29,7 \pm 0,1$ & $32,3 \pm 0,3$ & $43,9 \pm 0,3$ & $36,6 \pm 0,2$ \\
\hline & K & $5,20 \pm 0,24$ & $6,62 \pm 0,31$ & $5,91 \pm 0,22$ & $6,69 \pm 0,22$ & $7,40 \pm 0,30$ & $6,77 \pm 0,32$ \\
\hline & $\mathrm{Ca}$ & $11,7 \pm 0,2$ & $11,3 \pm 0,3$ & $11,7 \pm 0,2$ & $10,9 \pm 0,2$ & $14,7 \pm 0,2$ & $12,5 \pm 0,3$ \\
\hline & $\mathrm{Mg}$ & $0,86 \pm 0,12$ & $1,05 \pm 0,11$ & $0,94 \pm 0,10$ & $0,99 \pm 0,10$ & $1,27 \pm 0,31$ & $1,11 \pm 0,31$ \\
\hline \multirow[t]{5}{*}{$\mathrm{Abr} / 2007$} & $\mathrm{pH}$ & 5,89 & 6,02 & 7,48 & 7,19 & 7,36 & 6,36 \\
\hline & $\mathrm{Na}$ & $27,9 \pm 0,1$ & $28,6 \pm 0,2$ & $35,8 \pm 0,1$ & $38,9 \pm 0,2$ & $58,5 \pm 0,2$ & $64,7 \pm 0,1$ \\
\hline & K & $5,88 \pm 0,20$ & $5,83 \pm 0,12$ & $5,93 \pm 0,24$ & $5,93 \pm 0,22$ & $6,57 \pm 0,21$ & $6,50 \pm 0,20$ \\
\hline & $\mathrm{Ca}$ & $5,54 \pm 0,10$ & $5,64 \pm 0,10$ & $6,24 \pm 0,21$ & $6,19 \pm 0,21$ & $9,42 \pm 0,23$ & $9,97 \pm 0,20$ \\
\hline & $\mathrm{Mg}$ & $9,30 \pm 0,24$ & $8,88 \pm 0,20$ & $9,78 \pm 0,10$ & $10,4 \pm 0,1$ & $13,9 \pm 0,2$ & $14,5 \pm 0,2$ \\
\hline \multirow[t]{5}{*}{ Jul/2007 } & $\mathrm{pH}$ & 6,10 & 6,44 & 7,01 & 6,95 & 6,48 & 6,77 \\
\hline & $\mathrm{Na}$ & $12,9 \pm 0,1$ & $13,1 \pm 0,1$ & $13,2 \pm 0,1$ & $13,5 \pm 0,1$ & $13,8 \pm 0,1$ & $13,9 \pm 0,1$ \\
\hline & K & $6,33 \pm 0,22$ & $6,32 \pm 0,21$ & $6,22 \pm 0,10$ & $6,20 \pm 0,24$ & $6,42 \pm 0,33$ & $6,50 \pm 0,32$ \\
\hline & $\mathrm{Ca}$ & $6,98 \pm 0,10$ & $7,17 \pm 0,10$ & $7,83 \pm 0,20$ & $8,13 \pm 0,11$ & $11,1 \pm 0,2$ & $12,2 \pm 0,2$ \\
\hline & $\mathrm{Mg}$ & $3,61 \pm 0,22$ & $3,63 \pm 0,21$ & $3,66 \pm 0,32$ & $3,69 \pm 0,30$ & $3,74 \pm 0,10$ & $3,73 \pm 0,20$ \\
\hline
\end{tabular}
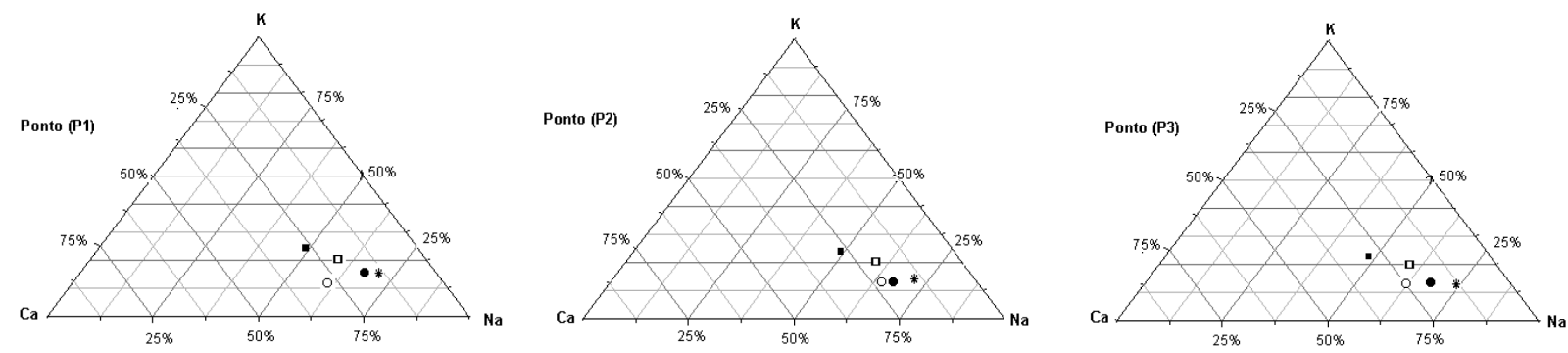

Figura 4. Diagramas ternários gerados a partir das concentrações de $\mathrm{Na}^{+}, \mathrm{K}^{+}$e $\mathrm{Ca}^{2+}$ nas amostras de água coletadas nos pontos $\mathrm{P} 1$, P2 e P3 nos períodos: Dez/2005 ( $\square$ ); Set/2006 (•); Nov/2006 (O); Abr/2007 (*); Jul/2007 (ש)

de $\mathrm{Na}^{+}, \mathrm{K}^{+}$e $\mathrm{Ca}^{2+}$, nos diagramas ternários, apresentam características bem diferentes quando comparados com os pontos que se localizam a montante do perímetro urbano da cidade de Jequié. Com isso é importante ressaltar que as chuvas que caem diretamente na superfície dos reservatórios representam uma simples diluição, mas as águas que são drenadas das chuvas que ocorrem na bacia hidrográfica, antes de chegar aos rios e reservatórios, caminham sobre a superfície das cidades, lixiviando o terreno (solos e sedimentos), interagindo a cada instante com o material com que entram em contato. Tais interações dependem principalmente do tempo de contato e das características da solução e do material, cada um variando no espaço e no tempo.
Os primeiros escoamentos da época chuvosa são geralmente mais concentrados por arrastarem as espécies químicas acumuladas..$^{20-25}$

\section{CONCLUSÕES}

Os resultados deste estudo mostraram que a concentração do sódio nas águas sofre influência somente do fator diluição, sendo por isso adequada como um ótimo indicador do processo de salinização dos recursos hídricos urbanos.

A influência da atividade urbana na qualidade das águas do Rio de Contas também é evidenciada com base no aumento da CE e STD ob- 

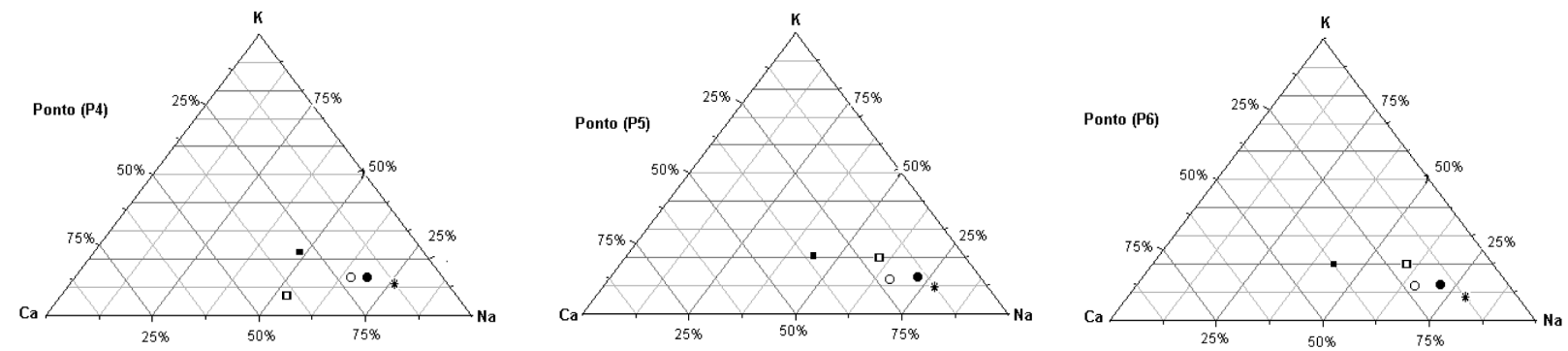

Figura 5. Diagramas ternários gerados a partir das concentrações de $\mathrm{Na}^{+}, \mathrm{K}^{+}$e $\mathrm{Ca}^{2+}$ nas amostras de água coletadas nos pontos P4, P5 e P6 nos períodos: Dez/2005 (口); Set/2006 (•); Nov/2006 (O); Abr/2007 (*); Jul/2007 (ש)

servados nas amostras coletadas no ponto P5, local que drena um grande volume de águas das precipitações que ocorrem na área urbana.

As elevadas concentrações de Ca nas amostras de água coletadas no período chuvoso (dez/2005), no ponto P4, podem ser atribuídas à influência de sua localização. Esse ponto está localizado exatamente na confluência do Rio de Contas com o Rio Jequiezinho, que drena boa parte dos esgotos sanitários e águas pluviais da cidade de Jequié. Com isso, esse elemento pode ser um bom indicador de aportes de esgoto sanitário e deflúvio urbano nas águas naturais.

\section{MATERIAL SUPLEMENTAR}

No material suplementar, disponível gratuitamente em http:// quimicanova.sbq.org.br na forma de arquivo PDF, com acesso livre, encontram-se os seguintes dados: mapa da área em estudo (Figura 1S) e fotografias dos pontos de coleta P1, P2, P3, P4, P5 e P6 (Figuras $2 \mathrm{~S}, 3 \mathrm{~S}, 4 \mathrm{~S}, 5 \mathrm{~S}, 6 \mathrm{~S}$ e $7 \mathrm{~S}$, respectivamente).

\section{REFERÊNCIAS}

1. Santos, J. S.; Oliveira, E.; Massaro, S.; Quim. Nova 2000, 23, 453.

2. Prathumratana, L.; Sthiannopkao, S.; Kim, K. W.; Environ. Int. 2008, 34,860 .

3. Santos, J. S.; Oliveira, E.; Bruns, R. E.; Gennari, R. F.; Water Res. 2004, 38,1579 .

4. Drever, J. I.; The Geochemistry of Natural Waters: Surface and Groundwater environments, $3^{\text {rd }}$ ed., Prentice Hall: Englewood Cliffs, 1997.

5. Raiswell, R. W.; Brimblecambe, P.; Dent, D. L.; Liss, P. S.; Environmental Chemistry, Ediciones Omega: Barcelona, 1983.
6. Lu, X. Q.; Werner, I.; Young, T. M.; Environ. Int. 2005, 31, 593.

7. Boiley, R. A.; Clark, H. M.; Ferris, J. P.; Krause, S.; Strang, R. L.; Chemistry of the Environment, Academic Press: New York, 1978.

8. Nguyen, H. L.; Leermakers, M.; Osán, J.; Török, S.; Baeyens, W.; Sci. Total Environ. 2005, 340, 213.

9. Morel, F. M. M.; Hering, J. G.; Principles and Applications of Aquatic Chemistry, John Wiley: New York, 1993.

10. Gaur, V. K.; Gupta, S. K.; Pandey, S. D.; Gopal, K.; Misra, V.; Environ. Monit. Assess. 2005, 102, 419.

11. Filgueiras, A. V.; Lavilla, I.; Bendicho, C.; Sci. Total Environ. 2004, 330, 115.

12. Maksoud, H.; Hidrologia e Possibilidades Hidroenergéticas da Bacia do Rio de Contas, na Bahia, IBGE: Rio de Janeiro, 1964.

13. Göbel, P.; Dierkes, C.; Coldewey, W.G.; J. Contam. Hydrol. 2007, 91, 26.

14. Chalmers, A. T.; Van Metre, P. C.; Callender, E.; J. Contam. Hydrol. 2007, $91,4$.

15. Ellis, P. A.; Mackay, R.; Rivett, M. O.; J. Contam. Hydrol. 2007, 91, 58.

16. Mahler, B.; Massei, N.; J. Contam. Hydrol. 2007, 91, 81.

17. Felipe-Sotelo, M.; Andrade, J. M.; Carlosena, A.; Tauler, R.; Anal. Chim. Acta 2007, 583, 128.

18. Caplat, C.; Texier, H.; Barillier, D.; Lelievre, C.; Mar. Pollut. Bull. 2005, $50,504$.

19. Fangueiro, D.; Bermond, A.; Santos, E.; Carapuça, H.; Duarte, A.; Talanta 2005, 66, 844.

20. Santos, J. S.; Santos, M. L. P.; Oliveira, E.; Quim. Nova 2008, 31, 1107.

21. Westall, J.; Stumm, W.; The Natural Environment and the Biogeochemical Cycles. The Hydrosphere, Springer: New York, 1984.

22. Perona, E; Bonilla, I.; Mateo, P.; Sci. Total Environ. 1999, 241, 75.

23. Bricker, S. B.; Sci. Total Environ. 1996, 179, 27.

24. Surija, B.; Branica, M.; Sci. Total Environ. 1995, 170, 101.

25. Michelcic, G.; Surija, B.; Juracic, M.; Borisic, D.; Branica, M.; Sci. Total Environ. 1996, 182, 105. 


\section{PARÂMETROS INDICATIVOS DO PROCESSO DE SALINIZAÇÃO EM RIOS URBANOS DO SEMI-ÁRIDO BRASILEIRO}

José Soares dos Santos*, Marcio José Silva dos Santos e Maria Lúcia Pires dos Santos

Departamento de Ciências Naturais, Universidade Estadual do Sudoeste da Bahia, Estrada do Bem Querer, km 4, CP 95 , 45083-900 Vitória da Conquista - BA, Brasil

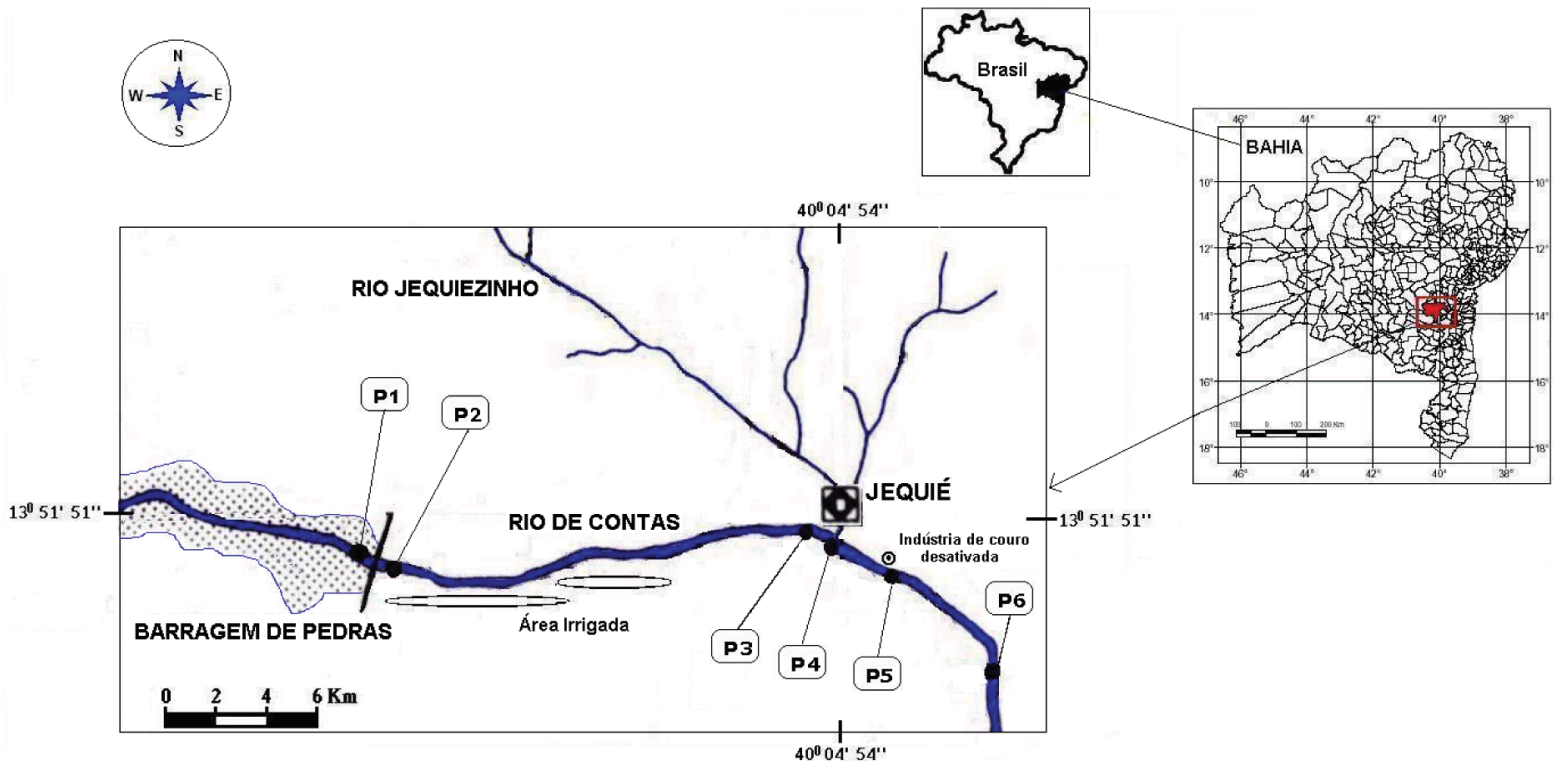

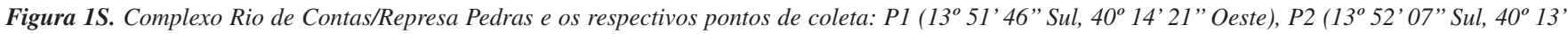

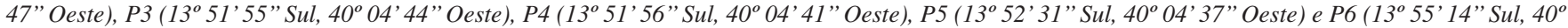
01'44" Oeste) 


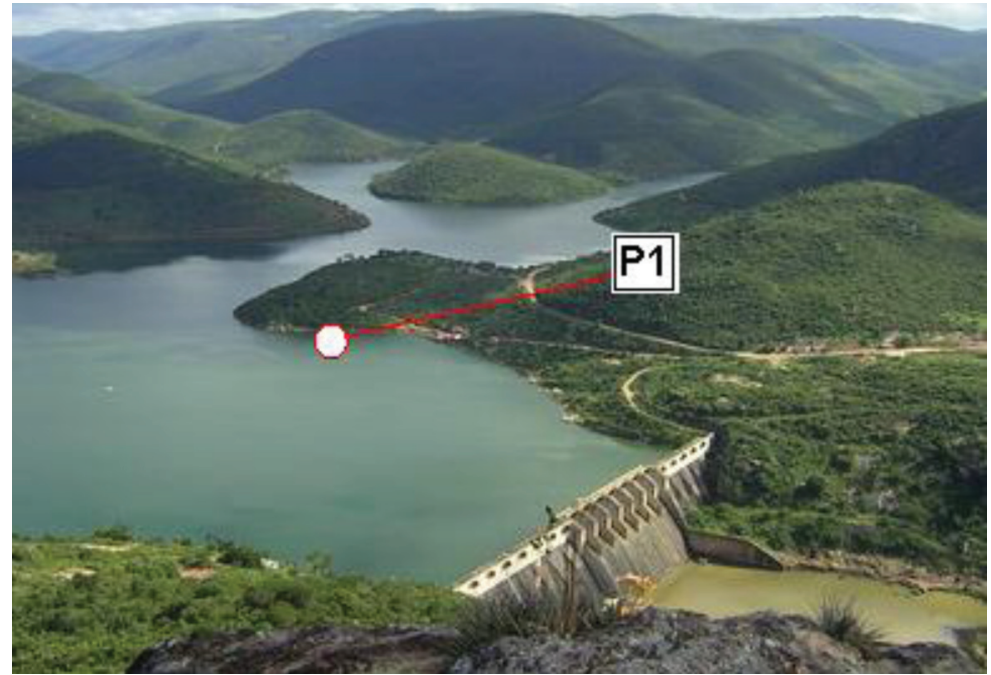

Figura 2S. Fotografia do ponto de coleta P1

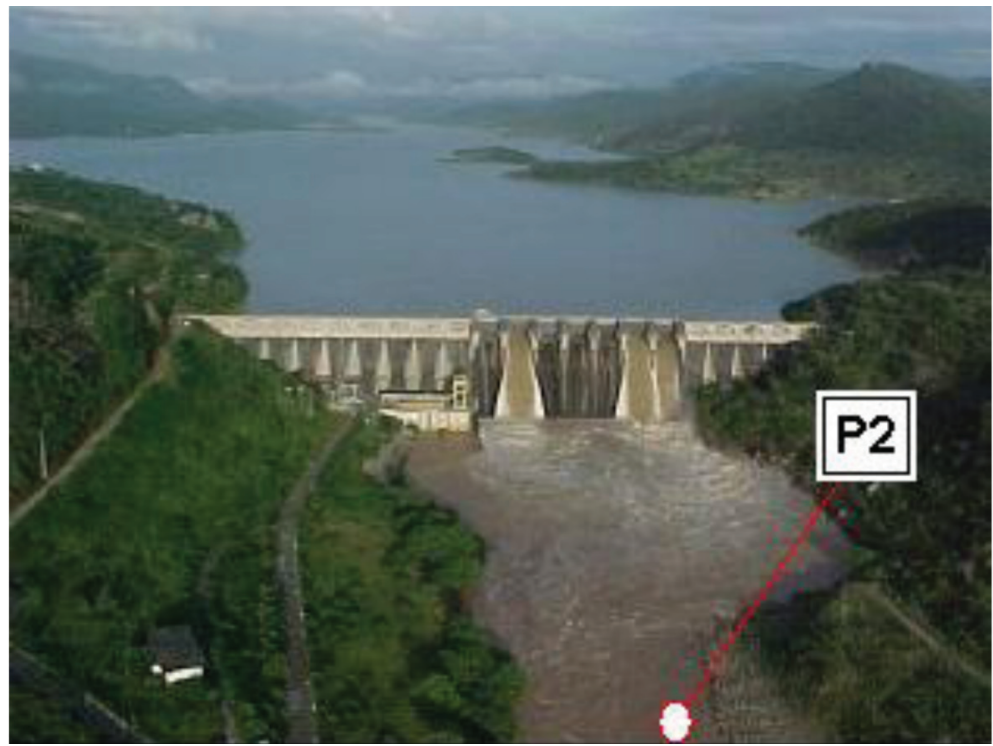

Figura 3S. Fotografia do ponto de coleta P2 


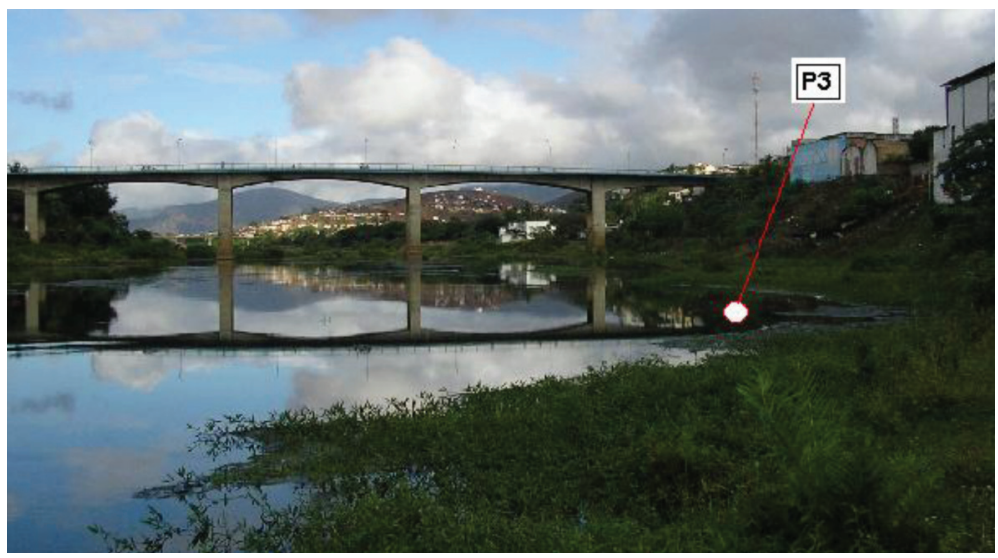

Figura 4S. Fotografia do ponto de coleta P3

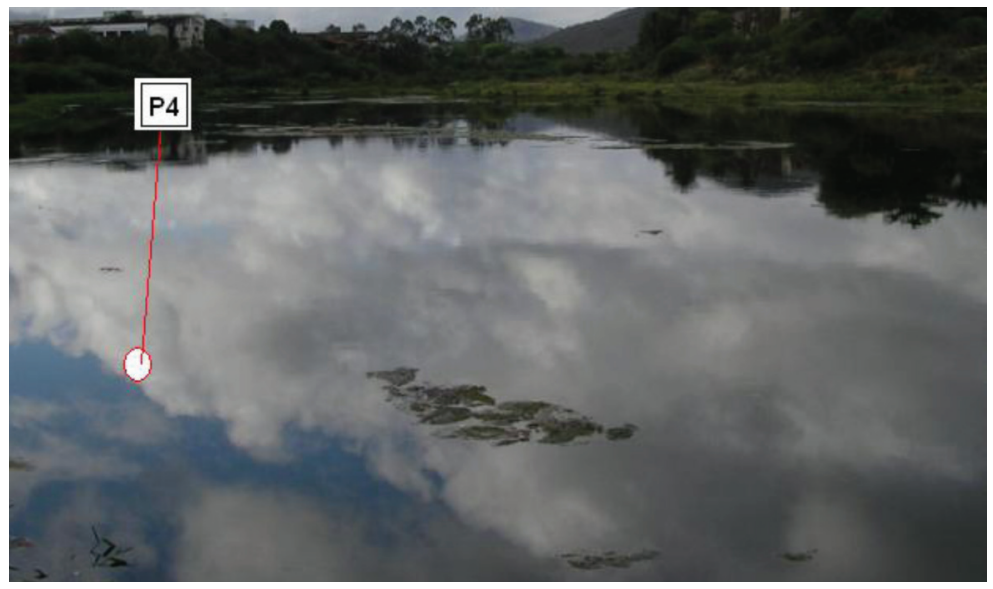

Figura 5S. Fotografia do ponto de coleta P4 


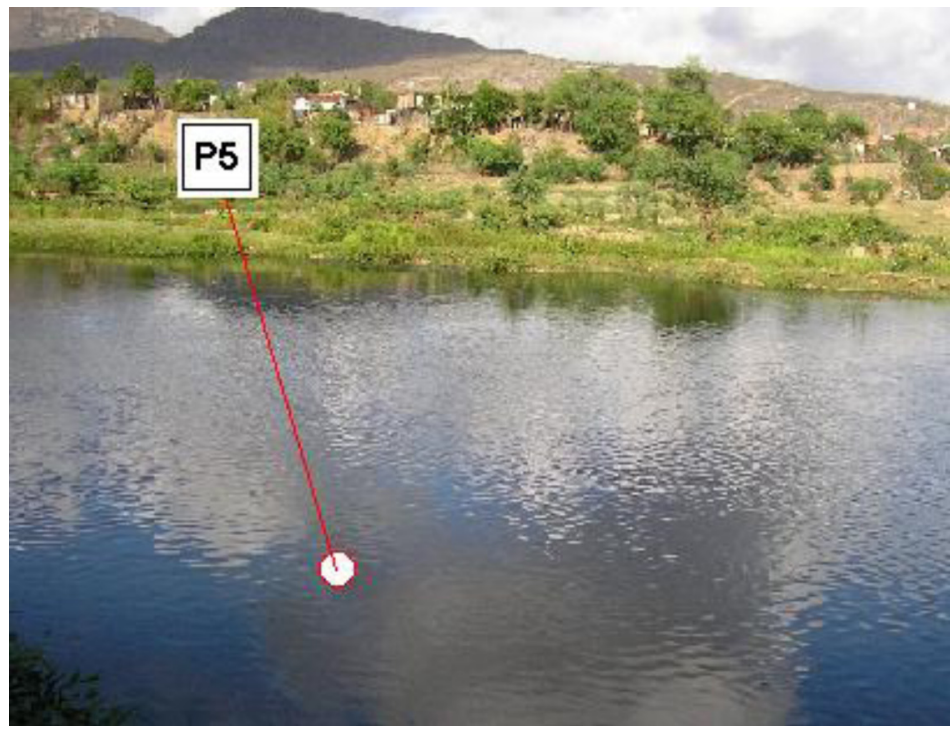

Figura 6S. Fotografia do ponto de coleta P5

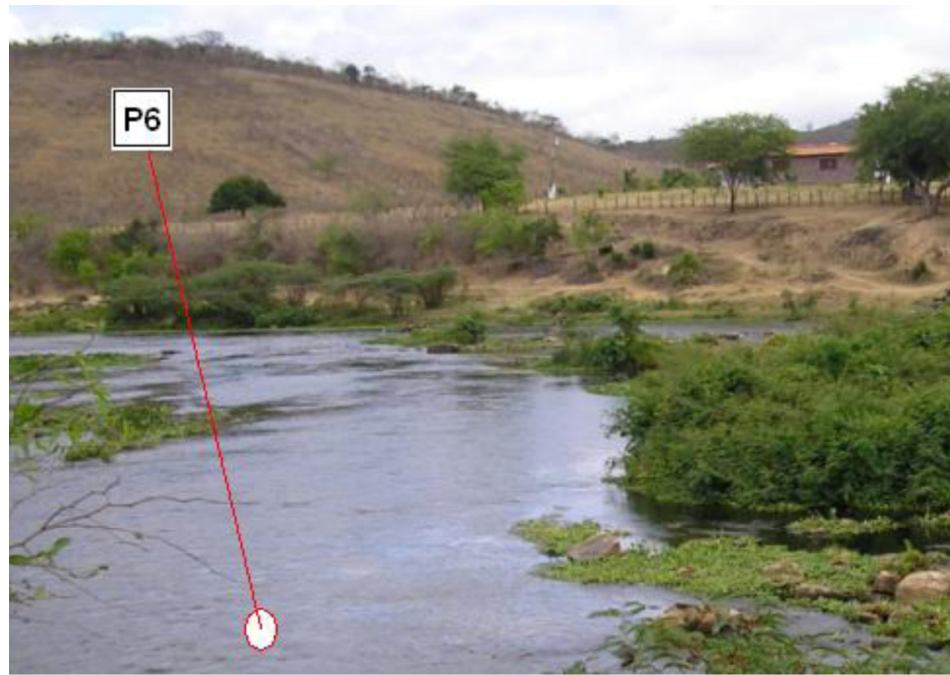

Figura 7S. Fotografia do ponto de coleta P6 